\title{
Lutas por autodefinição de subjetividades negras em contextos organizacionais: racismo, autoimagem e resistências afrodiaspóricas
}

Struggles for self-definition of Black subjectivities in organizational contexts: racism, self-image, and aphrodiaspora resistance Luchas por la autodefinición de subjetividades negras en contextos organizacionales: racismo, autoimagen y resistencias afrodiaspóricas

\section{Luciana de OLiveira}

Tem pós-doutorado em Antropologia Social pela Universidade de Brasília (UnB).

Doutora em Sociologia e Política pela Universidade Federal de Minas Gerais (UFMG).

Mestre em Antropologia pela UFMG.

- Graduada em Publicidade e Propaganda pela Pontifícia Universidade Católica de Minas Gerais (PUC-Minas).

- $\quad$ Líder do Grupo de Pesquisa Coletivo de Estudos, Pesquisas Etnográficas e Ações Comunicacionais em Contextos de Risco (Corisco).

- E-mail: Luciana.Lucyoli@gmail.com

\section{Ester Antonieta Santos}

Mestranda em Comunicação Social no Programa de Pós-Graduação em Comunicação Social da UFMG.

Psicóloga pela PUC-Minas.

- Aprendiz nas tradições afrodiaspóricas.

- Integrante do Corisco.

- E-mail: esterantonieta@gmail.com

(9) Fred Mendes

- Doutorando em Comunicação Social pelo Programa de Pós-Graduação em Comunicação da UFMG.

- Mestre em Estado, Governo e Políticas Públicas da Faculdade Latino-americana de Ciências Sociais (FLACSO).

- $\quad$ Administrador Centro Universitário Newton Paiva BH.

- Integrante do Corisco.

- E-mail: fredmendes@negrito.com.br

Washington Luís Santos Oliveira

Mestrando em Comunicação Social pelo Programa de Pós-Graduação em Comunicação da UFMG.

- $\quad$ Especialização em Comunicação e Informação Educacional e Empresarial (UNIFCV).

- Jornalista pela Faculdade Estácio de Sá de Belo Horizonte.

- $\quad$ Aprendiz nas tradições afrodiaspóricas.

- Integrante do Corisco.

- E-mail: washluissantos@gmail.com 


\section{Resumo}

Neste artigo, discutimos algumas tensões entre modulações discursivas antirracistas em contextos organizacionais em face a episódios de racismo e ações individuais de trabalhadores e trabalhadoras para denunciá-los e repará-los judicialmente. Metodologicamente, analisamos sete casos que tiveram visibilidade midiática a partir de busca no acervo da Folha de S.Paulo entre 2000 e 2021, nos quais verificamos operações discursivas das categorias consciência ocidental do negro (racismo) e consciência negra do negro (autodefinição), de acordo com o conceito de razão negra.

\section{PALAVRAS-CHAVE: RACISMO•AUTODEFINIÇÃO・RAZÃO NEGRA・CONTEXTOS ORGANIZACIONAIS.}

\section{Abstract}

This article discusses some tensions between anti-racist discursive modulations in organizational contexts before episodes of racism and individual actions of workers to denounce and redress them in court. To this end, the study investigated seven cases that reached media visibility, selected from a search in the Folha de São Pauloarchive (2000-2021), indicating discursive operations in the categories western Black consciousness (racism) and Black consciousness of Black people (self-definition) - according to the concept of Black reason.

KEYWORDS: RACISM・SELF-DENIFITION・BLACK REASON・ORGANIZATIONAL CONTEXTS.

\section{Resumen}

En este artículo discutimos algunas tensiones entre las modulaciones discursivas antirracistas en contextos organizacionales ante episodios de racismo y las acciones individuales de trabajadores y trabajadoras que involucran la denuncia y la reparación de tales acciones en los tribunales. Analizamos siete casos que tuvieron visibilidad mediática a partir de una búsqueda en las colecciones de Folha de S. Paulo en el período entre 2000 y 2021, y concluimos que hay operaciones discursivas de las categorías conciencia negra occidental (racismo) y conciencia negra del negro (autodefinición) según el concepto de razón negra. 


\section{INTRODUÇÃO}

$\mathrm{H}$ istoricamente, os movimentos de afirmação étnico-raciais ganharam extrema relevância a partir das lutas dos movimentos negros por direitos, com pautas abrangendo desde o direito de existir ${ }^{1}$ - com igualdade, dignidade e respeito - até 0 direito de ser e expressar uma imagem de si que não seja violentamente pautada pelas fabulações da branquitude supremacista, impostas através de suas várias armas: imagens de controle, sub-representatividade e outrificação/objetificação das subjetividades negras ou do povo negro como um conjunto homogêneo. No Brasil, os mecanismos de desconstrução da identidade afrodescendente são um empreendimento histórico construído desde o colonialismo oficial até as práticas de colonialidade contemporâneas. No século XX, especialmente a partir do fortalecimento das lutas do movimento negro, um forte debate sobre a imagem de corpos racializados vem ganhando espaço (Fanon, 2008).

Diversas gerações de africanos e seus descendentes, na batalha contra as diversas formas de opressão, saltaram das senzalas e dos movimentos abolicionistas para os movimentos urbanos no século XX, constituindo as frentes de luta do movimento político militante - que ganhou destaque nos anos 1970, a partir da chamada terceira fase do movimento negro (Domingues, 2007) -, projetando elementos étnicos e identitários como ferramentas de reafirmação (Lody, 2004) e instrumentos de luta contra a invisibilizarão (Leite, 1996), bem como de aprofundamento dos sentimentos de autoestima e pertencimento, com consequente subjetivação política de negros e negras (Figueiredo, 2015; Pinho, 2006). É importante pensar que cada uma destas gerações foi ampliando o espaço de debate e se colocando em novos lugares. Nos anos seguintes, importantes trabalhos recuperaram e situaram a questão da imagem negra, ampliando social e academicamente a discussão e, neste último âmbito, irradiando o debate para muitos campos de pesquisa.

No campo das políticas públicas, a força da síntese do pensamento sobre o racismo possibilitou importantes marcos, como a criação da Fundação Cultural Palmares, em 1988; o reconhecimento de Zumbi dos Palmares como herói, em 1995; 0 lançamento de uma série de editais afirmativos em áreas como cultura, cinema, educação e saúde; a inclusão do ensino da história e da cultura afro-brasileira e africana no Brasil com a Lei 꾸10.639, de 9 de janeiro de 2003, e a criação da Secretaria de Políticas de Promoção da Igualdade Racial (Seppir), também no ano de 2003, que foi possivelmente o marco institucional mais importante da história das lutas antirracistas no Brasil depois da abolição.

Entretanto, apesar de grandes avanços desde os anos 1970, a condição de negros e negras continua precária. 0 tema que, no início do século XXI, foi das ruas para o debate político governamental, só nos últimos anos vem adentrando vagarosamente as empresas e exigindo transformações em políticas de desenvolvimento humano e organizacional, compliance e responsabilidade social, pautando as questões raciais. Ainda assim, tais ações empresariais não são suficientes para combater o racismo estrutural e, muitas vezes, não conseguem sair do nível normativo nem ultrapassar os limites neoliberais do politicamente correto para alcançar efetividade no enfrentamento dos privilégios raciais.

A condição dos afrodescendentes é retratada em diversas pesquisas que, variando os recortes e temáticas, sempre apontam os piores indicadores de desenvolvimento humano, social, educacional e econômico entre grupos racializados. Segundo dados do IBGE'2, no ano de 2016 a taxa de analfabetismo entre brancos era de 4,2\% e entre pretos e pardos era de 9,9\%. Dentre 1.835 crianças de 5 a 7 anos que já trabalhavam, 35,8\% eram brancas e 63,8\% eram pretas ou pardas. 0 rendimento médio de todos os trabalhos no ano de 2017 era de $\mathrm{R} \$ 2.814$ para brancos, $\mathrm{R} \$ 1.606$ para pardos e $\mathrm{R} \$ 1.570$ para pretos e, neste mesmo

1 De acordo com os dados do Mapa da Violência do IPEA (2020), um jovem negro é morto no Brasil a cada 23 minutos.

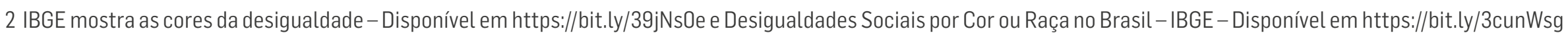


ano, taxa de desocupação entre pessoas brancas era de $9,5 \%$, entre pessoas pardas, $14,5 \%$ e entre pessoas pretas, $13,6 \%$. Em 2018, a distribuição da população por cor ou raça no Brasil representava 43,1\% de pessoas brancas, 55,8\% pretos e pardos. Em relação à quantidade populacional por gênero, homens brancos totalizavam $42,3 \%$ e mulheres brancas, $44 \%$, enquanto homens pretos e pardos, $56,6 \%$ e mulheres pretas totalizavam $55 \%$ da população nacional. Nos cargos gerenciais, $68,6 \%$ eram ocupados por brancos e $29,9 \%$, por pretos ou pardos.

Estes dados só demonstram, resumidamente, esta cena e o quanto as dificuldades estão presentes no cotidiano de negros e negras, concretizando o racismo. Incrustadas nas práticas discursivas de poder organizacional - 0 que inclui dress codes, regras de aparência e a sutileza das "sugestões" hierarquizadas de assumir uma "boa" aparência em nome do emprego -, as práticas do racismo exigem de sujeitos e sujeitas negras posturas empoderadas ou modos de subjetivação política a partir dos quais erguem a voz e expressam a si mesmas para serem reconhecidas por sua autodefinição (Collins, 2018; hooks, 2019).

Nesta esteira, as relações entre empregabilidade, imagem afro e racismo tornaram-se mais evidentes, e o debate sobre esta questão tem ganhado grande repercussão e influenciado as dinâmicas sociais que, nesta toada, reforçam a necessidade de mudança nas culturas organizacionais empresariais (Marchiori, 2008). Partindo da relação entre comunicação, discurso e complexidade (Baldissera, 2009; Batista; Baldissera, 2010), bem como da relação entre contextos organizacionais e modulações discursivas (Jamison; Santos, 2017; Oliveira; Marques, 2012; Oliveira; Siqueira, 2014). 0 artigo busca, então, examinar casos que ganharam visibilidade midiática nos quais houve tensões ocasionadas por episódios de racismo nas operações discursivas organizacionais contra trabalhadores e trabalhadoras que ergueram suas vozes e denunciaram o racismo por meio de ações na Justiça do Trabalho. Focamos nossa busca por esses casos no portal da Folha de S.Paulo, dada a sua representatividade no cenário dos veículos de informação nacionais, e, a partir dela, identificamos um conjunto de sete casos. Como modo de analisar as matérias, após a sua leitura e junto com a construção do referencial teórico, observamos se delinearem dois operadores analíticos de nosso material empírico resultantes do conceito de razão negra (Mbembe, 2018): de um lado, as formas do racismo modalizadas segundo discursos organizacionais da "consciência Ocidental dos sujeitos/das sujeitas racializadas"; e, de outro, as formas de resistência de pessoas negras que, na condição de trabalhadoras constrangidas nas regras hierárquicas a mudar sua aparência sob o risco de perder o emprego ou de serem simplesmente demitidas, buscaram se autodefinir a partir de denúncias judiciais de discriminação racial, afirmando a "consciência negra dos sujeitos/das sujeitas negras".

\section{A ENGENHARIA RACISTA E A NEGRITUDE COMO CONTRAGOLPE}

Analisar e relacionar o cenário corporativo e o mundo do trabalho, nos quais se proliferam desrespeitos à estética e ancestralidade dos negros e negras requer, antes de tudo, compreender que o que está em questão é o racismo em uma de suas manifestações, e qualquer discussão que o tenha como pano de fundo deve levar em conta que essa estrutura perniciosa se vale de um movimento muito eficaz, historicamente construído, de desvalorização e desumanização do negro e da negra a partir de seu nome, sua história, suas experiências religiosas, sua cultura, suas características (Moore, 2007). 0 modelo de quebra da identidade e pluralidade negra é empregado com vistas ao esvaziamento e à redução do homem/mulher/ criança a uma coisa ou, nas operações de desumanização capitalísticas, numa mercadoria. Não é à toa que os movimentos teóricos decoloniais e pós-coloniais contemporâneos têm tratado de discutir o elo epistêmico entre raça/racismo, filosofia e capitalismo ${ }^{3}$. Tal elo coloca o Ocidente europeu como centro do globo, terra natal da razão, da vida universal e da verdade, rincão mais civilizado do mundo e o resto do mundo como dessemelhante, como diferença que opera o poder do negativo, existência objetificada. Segundo Mbembe (2018):

3 Hegel (apud Mbembe, 2018, p.27), por exemplo, descreve as pessoas negras: "estátuas sem linguagem nem consciência de si; entes humanos incapazes de se despir de uma vez por todas da figura animal com a qual se confundiam. No fundo, era da sua natureza abrigar o que já estava morto". 
Vista em profundidade, a raça é ademais um complexo perverso, gerador de temores e tormentos, de perturbações do pensamento e de terror, mas sobretudo de infinitos sofrimentos e, eventualmente, de catástrofes. Em sua dimensão fantasmagórica, é uma figura da neurose fóbica, obsessiva e, por vezes, histérica. De resto, consiste naquilo que se consolida odiando, manejando o terror, praticando o alterocídio, isto é, constituindo o outro não como semelhante a si mesmo, mas como objeto propriamente ameaçador, do qual é preciso se proteger ou desfazer, ou ao qual caberia simplesmente destruir, na impossibilidade de assegurar seu controle total. Mas como explica Frantz Fanon, raça é também o nome que se deve dar ao ressentimento amargo, ao irrepreensível desejo de vingança, isto é, à raiva daqueles que, condenados à sujeição, veem-se com frequência obrigados a sofrer uma infinidade de injúrias, todos os tipos de estupros e humilhações e incontáveis feridas.

A tara, sobretudo do pensamento colonial, que se expandiu e que continua plenamente ativa no tecido social contemporâneo moderno/colonial, sempre considerou as identidades não como copresenças, como convívio em uma casa comum, mas como espelho que reflete uma única imagem ideal que em tudo precisa se assemelhar ao referente idealizado. Esse fato se deve, como bem nos ensina Achile Mbembe (2018, p.11): "ao fato de o negro ser aquele que vemos quando nada se vê, quando nada se compreende e nem se deseja, em qualquer lado que apareça".

Essa maneira de conceber um ser vazio, em que nada se aproveita, cujos valores e cultura são subalternizados, conhecimentos desconsiderados, a imagem ridicularizada - desejada apenas no campo do fetiche sexual ou no campo econômico em que 0 valor total de seu trabalho possa ser extraído - encontrou no capitalismo a força necessária para disseminar a objetificação de negros e negras. A objetificação e a outrificação (Collins, 2018; hooks, 2019; Mbembe, 2018) foram modos de operação dos binarismos ocidentais nos quais as pessoas negras são aproximadas do polo da natureza e, portanto, da animalidade como justificativas à sua subordinação aos brancos. Nesse movimento, as características étnico-raciais são fabuladas como indesejáveis, negativas, feias e sujas.

Tais processos históricos de construção da ideia de raça e do racismo têm profundas consequências sobre as subjetividades negras. A principal é que tais subjetividades são experienciadas como um duplo que considera tanto o olhar opressor e 0 modo como ele vê, quanto o olhar que é próprio e vê, nos espaços íntimos e interiores da consciência negra, quem se é. É em face disso que Mbembe (2018) explica o funcionamento da razão negra, a partir de dois textos ou campos discursivos que operam simultaneamente. 0 primeiro texto inquire "quem é esse" e diz da consciência ocidental do negro ou se proclama como um juízo de identidade. Segundo o autor, "codifica as condições de manifestação de um sujeito racial: quem é ele? Como o reconhecemos? 0 que o diferencia de nós? Poderá ele se tornar nosso semelhante? Como o governar e para que fins?" (Mbembe, 2018, p.61). Respondendo a tais perguntas, a razão negra constrói discursos e práticas num trabalho cotidiano de invenção do negro como sujeito racial e exterioridade selvagem. Mas a razão negra se constitui também de um segundo texto que inquire "o que sou eu", desvelando a consciência negra do negro que se proclama como declaração de identidade. Através dele, o negro diz de si mesmo ser aquele sobre o qual não se exerce domínio; aquele que não está onde se diz estar, muito menos onde é procurado, mas sim ali onde não é pensado. Assim, mais do que uma resposta ao primeiro texto, é um gesto de autodeterminação, modo de presença perante si mesmo, olhar interior e utopia crítica (Mbembe, 2018, p.62)

O pensamento feminista negro tem se ocupado detidamente do tema da autodefinição. Talvez pelo fato de que a dupla opressão - gênero e raça - rebata sobre os corpos racializados das mulheres de maneira mais incisiva - duplamente conectadas ao pólo da natureza e duplamente outrificadas na cultura ocidental patriarcal e branca. Às pessoas negras, especialmente às mulheres negras, aplica-se o pensamento de Lorde (apud Collins, 2018, p.179): "para sobreviver, sempre tivemos que estar vigilantes". Tal pensamento enuncia como a dupla consciência opera nas afro-americanas que, segundo a autora, "se familiarizam com a linguagem e as maneiras de agir do opressor, chegando às vezes a adotá-las por certa ilusão de proteção". Ao mesmo tempo que esconde um ponto de vista autodefinido dos olhos curiosos dos grupos dominantes, a dupla consciência nada mais é do que viver duas vidas: uma própria e uma para o outro. bell hooks (2019), também interessada nas relações 
entre olhar e poder, nos diz que, como sujeito, toda pessoa tem o direito de definir sua própria realidade, estabelecer sua própria identidade e dar nome à sua própria história. Para Collins (2018, p.138), esse "direito deveria fazer parte de todas as constituições de todos os países do mundo".

No Brasil, as operações coloniais-racistas e suas permanências ainda no presente consagraram o ideal de convivência harmônica entre as raças, mascarado pela ideologia da democracia racial. 0 grande número de mestiços e a ausência de segregação racial oficial foram os indícios mais utilizados para reforçar tal ideologia, além de sua fundamentação histórica no suposto "caráter ibérico", mais aberto à convivência com as diferenças do que o de outras nações colonizadoras. No entanto, como analisa Figueiredo (2015):

\footnotetext{
A partir do final dos anos 1970, os ativistas negros brasileiros e alguns pesquisadores americanos ofereceram uma outra perspectiva. Para eles, o racismo no Brasil é pior do que o existente nos Estados Unidos, já que aqui as desigualdades sociais caminham lado a lado com o discurso da democracia racial e da mestiçagem, o que dificulta, sobremaneira, que os negro-mestiços no Brasil tenham consciência da sua condição social estar relacionada à sua condição racial e, consequentemente, assumirem a identidade negra. É importante destacar aqui a relevância atribuída as categorias da cor presente no modelo racial brasileiro em que as denominações da cor ou da raça estavam associadas aos fenótipos, daí a importância atribuída à escala classificatória e da autoclassificação da cor. (Figueiredo, 2015, p.155)
}

A ideia de negritude surge como um movimento de reconexão com valores, ensinamentos e estéticas ancestrais do povo preto como símbolos de pertença, de resistência, ressignificada ao longo dos anos por diversos movimentos negros mundo afora. Nesse contexto, voltar às origens tendo como um dos elementos ver a si e dar-se a ver como um eu a um só tempo autônomo e coletivo, o cuidado e a manutenção da imagem afrocentrada é, acima de tudo, uma forma de resistência, é declarar guerra aos hostis que, ainda hoje, se servem do racismo para suas ações. Os movimentos negros que afirmaram a ideia de negritude trabalharam, a partir dos anos 1970, segundo Figueiredo (2015), a desarticulação da celebração da mestiçagem e do uso de termos identitários branco-negro no modelo político bipolar. Nesse sentido é que ganha força a noção de identidade, não como conceito sociológico essencialista ou de criação de exceções políticas numa ordem universal, mas como afirmação de si e de um eu coletivo nas arenas públicas como forma de exercício de autodefinição, liberdade e cidadania plena. Em contraponto a toda uma engenharia racista que se ancorou numa homogeneização da experiência negra para cruelmente desconsiderar a pluralidade, Munanga (1988) enfatiza a experiência da negritude como uma complexidade compósita "englobando fatores históricos, psicológicos, linguísticos, culturais, político-ideológicos e raciais” (Munanga, 1988, p.143-146).

\section{RACISMOS EM CONTEXTOS ORGANIZACIONAIS: ESTUDO DE CASOS}

Contextos organizacionais são complexos: ao mesmo tempo que dialogam com os contextos culturais e socioeconômicos mais amplos dos cenários locais e globais, são também geradores de quadros autônomos de comportamentos e interações ou culturas organizacionais (Marchiori, 2008). Tal complexidade (Baldissera, 2009) tem sido objeto de estudo que se relaciona com as práticas discursivas entramadas em relações de poder e interações comunicativas nos fluxos entre o dentro e o fora das organizações (Oliveira; Marques, 2012; Oliveira; Siqueira, 2014). Nesse sentido, a comunicação é um processo que envolve a construção e a disputa de sentidos e, por isso, Batista e Baldissera (2010) lembram que o discurso organizacional comporta pelo menos três dimensões articuladas: a organização comunicada, a organização falada e a organização comunicante. A partir de um pensamento fundado na noção de complexidade, os autores propõem que, em uma primeira dimensão, 0 discurso organizacional é aquele que a organização diz de si mesma, presente nos seus documentos públicos e naqueles que circulam internamente, bem como em suas falas oficiais/institucionais. Numa segunda dimensão, destaca-se a organização comunicante, proveniente dos fluxos comunicacionais nos âmbitos formais e informais a partir das convocações propostas pela 
organização aos seus públicos e dos públicos em relação a uma organização, dizendo respeito ao modo como a organização vive e é experienciada. E, finalmente, numa terceira dimensão, está o que os autores chamam de organização falada, ou seja, aquela que aciona falas dos mais diversos sujeitos individuais e coletivos em relações diretas ou indiretas com a organização que, a partir de diversos contextos, meios e linguagens, formulam opiniões e fazem proferimentos públicos sobre ela.

Ao evocar a noção de modulações discursivas (Jamison; Santos, 2017), é essa tripla dimensão comunicacional das organizações e as variações da operação discursiva do racismo que gostaríamos de salientar. Visamos examinar como determinados recursos linguísticos atuam nas práticas discursivas do racismo nos contextos organizacionais e como foram apresentadas - na justiça do trabalho e na mídia - por suas vítimas Enquanto crescem a presença de códigos de conduta e as pressões por necessidades de atenção e combate ao racismo em contexto organizacional no nível da organização comunicada, 0 racismo não diminui enquanto prática discursiva na organização comunicante nem ganha as devidas respostas, em termos institucionais, para que inexista, sendo então denunciado no âmbito da dimensão da organização falada. No caso da presente pesquisa, a organização é falada num meio de comunicação de massa pela via de reportagens que vocalizam a visão das práticas discursivas do racismo do ponto de vista de pessoas que o sofreram em contextos organizacionais.

Para entender a insistente presença de racismo nos contextos organizacionais, procedemos a uma busca em jornais e em seus portais de notícias por casos judicializados que denunciam o racismo em contextos organizacionais diversos feitas por ex-funcionários/ex-funcionárias, a partir dos anos 2000. Tal recorte temporal justifica-se pelo contexto político brasileiro, conforme explicitado na introdução, no qual, por pressão dos movimentos sociais negros, alicerçam-se políticas públicas de combate ao racismo.

A busca mais relevante numericamente foi a que realizamos no mecanismo de busca booleana do UOL/Folha de S.Paulo e no Google com as palavras-chave assim combinadas: "racismo" and "trabalhador" and "empresa" and site:folha.uol.com. br. Reiteramos a escolha pelo portal UOL/Folha de S.Paulo por ser a plataforma de notícias on-line com maior número de assinantes no Brasil ${ }^{5}$. A primeira busca retornou 33 resultados e a segunda, 255. A partir de uma comparação entre a primeira - mais precisa de acordo com nossa problematização - e a segunda - mais ampla e com reportagens diversificadas sobre pesquisas, opiniões e casos de racismo não judicializados - e excluindo repetições é que chegamos a um recorte de sete casos. Vale dizer que o objetivo de nossa análise não é quantitativo, mas qualitativo. Observamos as modulações discursivas oriundas de práticas racistas em contextos organizacionais e as modulações discursivas de práticas de autodefinição por parte de sujeitos e sujeitas negras.

Dentre os sete casos a serem analisados, seis são de mulheres e apenas um é de homem, confirmando tendências das asserções do pensamento feminista negro quanto ao peso da dupla opressão sobre as mulheres negras. Uma reportagem é de 2001, uma de 2007, duas de 2011 e três de 2020. Geograficamente, as denúncias de racismo em contextos organizacionais judicializadas estão distribuídas pelos estados de Amapá (1), Minas Gerais (1), São Paulo (2), Rio de Janeiro (1), Pernambuco (1) e Mato Grosso (1). 0 tipo de contexto organizacional também é diversificado e inclui, dentre as organizações privadas: clínica médica, empresa de limpeza, comércio atacadista, rede de farmácias, comércio de alimentos e transportadora; além de uma empresa pública de saneamento.

No quadro 1, buscamos sistematizar, de forma sintética, o mecanismo da razão negra, destacando tanto algumas das modulações discursivas do racismo quanto das modulações discursivas da autodefinição de trabalhadoras negras.

4 Disponível em: https://busca.folha.uol.com.br/.

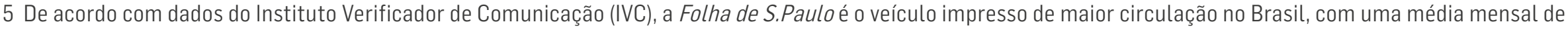
328.438 exemplares. O UOL é considerado pela Comscore a maior empresa de conteúdo, tecnologia, serviços e meios de pagamentos digitais do Brasil. 


\section{Quadro 1: Modulações discursivas contemporâneas da razão negra em contextos organizacionais brasileiros}

(1)

Karina Carla x clínica médica

Nova Lima - MG

(2)

Regina Santana da Silva x empresa de limpeza

Cuiabá - MT
"Não dá para você trabalhar com ele [o cabelo com tranças], fica muito informal mesmo, sabe, tem até uns penteados, alguns cortes de cabelo que, de fato, são dress code de empresa muito casual, muito informal, [e] não se enquadra tipo em banco, clínica médica, essas coisas", disse a consultora, que ainda afirmou que mandaria outra profissional até a clínica no dia seguinte "pra poder ensinar a fazer uns coques, algumas coisas pro dia a dia".
"A trança, além de me ajudar na transição capilar, faz parte da minha identidade e cultura."

"Falo com eles [os dois filhos adolescentes] o mesmo que falo para outras pessoas: 'Não se calem, lutem e não aceitem'."

"Acredito que lutando por crenças e valores, podemos tornar igual o que é igual, mas é tratado com preconceito".

"Demissão afetou seu estado emocional"

"Busca apoio da família, da mãe de santo e de membros do terreiro que frequenta"

"Além de ser negra, é macumbeira."

"O que machuca bastante, enquanto eu, Regina é sobre você não conhecer uma religião. Digo, a pessoa não conhecer a religião e indagar assim, com as palavras: 'nego macumbeiro'".

Um colega escreve num avental da empresa: "só para branco usar".

Nataly Ventura x Atacadão

(Grupo Carrefour)

Rio de Janeiro - RJ

(4)

Marianne Guimarães x Rede de Farmácias Extrafarma

Macapá-AP

(5)

Renata Ribeiro de Almeida $x$ Intercontinental Transportation LTDA São Paulo - SP
(6)

Tatiana Moreira Diniz X McDonald's Brasil São Paulo - SP

Armando S. de Oliveira $x$ Compesa Recife - PE
Nataly denuncia o ocorrido à sua chefia, que ordenou que a ofensa fosse apagada. Posteriormente, a vítima foi desligada da empresa.
Gerente da Rede: "A., como é branquinha, ficará pela manhã. 0 [...], como ele já é um pouco mais clarinho, ele fica à tarde. E tu [Marianne], como já és mais pretinha, fica na escuridão, à noite, que combina contigo".
"Burra"; "analfabeta"; "imprestável";

"aquela macaca não sabe fazer nada".

"única pessoa registrada como faxineira exercendo a função de recepcionista, única negra no setor."
"Duvidei muito que conseguiria ganhar a causa, mas não custava tentar. Aguentar aquilo era horrível."
Marianne não aguentou a pressão e pediu demissão e denunciou a prática da rede de farmácias no Ministério Público do Trabalho. contra a empresa após denúncias de racismo e intolerância religiosa feitas por Nataly.

\section{"preta fedida"}

"não gosto de pretos e de pobres"

"Gerente racista não foi demitida porque alguns de seus familiares exercem cargos altos na McDonald's Brasil".

Gerente fazia piadas contra os negros e dizia que iria "clarear o setor" que comandava.

Gerente perseguiu outros dois servidores negros.
A vítima denunciou a empresa no Ministério Público do Trabalho. 
No caso 1 (Siqueira, 2020), ao voltar de férias com um novo visual, a trabalhadora, que passou a usar tranças afro, foi notificada que o visual não combinava com o dress code da organização. Chegou a ser advertida pela "consultora de imagem" da empresa que deveria usar os cabelos de uma maneira "mais formal". A manifestação preconceituosa, no entanto, foi sutil, como anotou o juiz do caso em sua sentença, já que não houve nenhuma declaração direta quanto ao estilo afro do penteado.

Já no segundo caso (Rodrigo, 2020), o mecanismo racista diversifica-se um pouco. A imagem da trabalhadora foi considerada destoante porque ela raspou os cabelos após a iniciação no Candomblé, colocando em tela a violência do racismo religioso. Seus direitos foram cerceados por demarcar em sua imagem a adesão a uma religião de matriz africana. A trabalhadora previu que isso pudesse acontecer e tentou esconder sua identidade religiosa, mas foi descoberta pela chefe. Além, disso, o fato de ser negra constituiu um motivo destacado e declarado para que fosse "penalizada", reiterando o fetiche de controle do corpo negro. Este é um mecanismo clássico, um empreendimento histórico da colonialidade que remonta à forma como os europeus lidavam com africanos escravizados desde o século XVI na busca por justificar as opressões na cor da pele e tentar anular a identidade cultural e religiosa como forma de exercer soberania sobre o outro, conforme argumentamos na segunda seção.

0 terceiro caso foi objeto de duas matérias diferentes (Bérgamo, 2020a; Bérgamo, 2020b). Em comum, apresentam a objetificação do corpo negro como modo de operação racista. A trabalhadora foi hostilizada no trabalho por colegas. Dentre as atitudes relatadas, um colega escreveu no avental da trabalhadora "só pra branco usar". Após reclamar do que ocorria, a empresa, em vez de investir na transformação da cultura organizacional, resolveu demiti-la. Neste caso, ainda é possível ver que, na sua defesa, a empresa declara ter políticas antirracistas, mas que estas têm pouca ou nenhuma efetividade, reiterando que os códigos corporativos podem mascarar e reforçar diversos preconceitos, incluindo o racismo. Percebe-se também a sutileza e efetividade das ferramentas de discriminação racial: a empresa afirma que a trabalhadora foi demitida por avaliação negativa, tentando desconstruir que a razão de tal conduta avaliativa seja diretamente marcada pela questão étnico-racial, pela necessidade de "se livrar" de conflitos étnico-raciais internos, penalizando a vítima dos conflitos.

No quarto caso (Struck, 2011), é relatado que a escala de trabalho era construída a partir da intensidade da cor da pele dos colaboradores. Assim, quanto mais escuro, pior era o horário alocado. Como mostrou-se comum nos casos analisados, apesar da denúncia da vítima, não houve providência contra esta forma racista de alocar as pessoas em suas posições de trabalho. Em uma fala destacada da ação, a gestora informa que a trabalhadora poderia trabalhar no pior turno, à noite, por ser negra e combinar com a escuridão.

No quinto caso (Justiça..., 2007), a trabalhadora é chamada de "macaca", "analfabeta" e "imprestável" pela chefia. Um questionamento interessante é feito no início da matéria: haveria indenização ideal para crime de racismo? A questão discutida neste caso retoma as disputas de poder em torno do gesto discriminatório, concretizadas na falta de materialidade comprovada, para além da palavra da vítima. A mentalidade racista demonstrada no caso buscou não apenas diminuir e animalizar a vítima, como também operou desvantagens objetivas, como o registro em carteira com função de menor remuneração. No caso, a trabalhadora foi registrada como faxineira, mas atuava como recepcionista.

O sexto caso (Ripardo, 2002) mostra que a questão da impunidade permanece e como a comunicação violenta é empreendida sobre os corpos racializados. A gerente de uma franquia McDonald's, que afirmava não gostar de negros e pobres, maioria dos trabalhadores da área operacional e de atendimento da empresa, não foi punida por sua ação racista e por, dentre outras, chamar a trabalhadora de "preta fedida". A adjetivação negativa de características étnicas do negro também é um mecanismo histórico usado para outrificar corpos racializados. Neste caso, o juiz destacou que a marca global de fast-food tem códigos específicos que normatizam tais condutas na sua sede, nos Estados Unidos, e que esta cultura é extensível às suas operações em outros países. Isso enfatiza como muitas regras corporativas são construídas apenas como formas de proteção legal da empresa, sem se preocupar em gerar efeitos reais, reforçando o mascaramento e, decorrente disso, o poder de marginalização empreendido, no caso, pela discriminação racial. 
No sétimo caso (Guibu, 2001), a tentativa de prejudicar um negro no trabalho também é demonstrada tanto pela comunicação violenta, expressa em afirmativas que reiteravam a intenção de "clarear o escritório", quanto por ações gerenciais que pudessem culpabilizá-lo, como sua alocação naárea de suprimentos, onde, sabidamente, estavam sumindo itens de escritório. Na interpretação do denunciante, a ideia era atribuir a ele a responsabilidade pelo desaparecimento dos suprimentos e prejudicá-lo no trabalho. Neste caso, percebe-se a conjugação poderosa do racismo: ao fazer a denúncia do chefe que tinha tais posturas, o servidor foi expulso do setor e o agressor nem respondeu a processo administrativo pelo caso. Só após litigar na justiça do trabalho foi que o funcionário conseguiu se desfazer do registro negativo em sua ficha funcional e ser transferido. A instituição, mais uma vez, foi solidária com o gesto racista.

As questões trazidas em todos os casos evidenciam algumas operações implementadas pela racionalidade racista que, não obstante todos os posicionamentos e medidas institucionais antirracistas em contextos organizacionais, persistem em oprimir corpos racializados e constituir desvantagens objetivas para estas pessoas. Este modus operandié implementado por determinados dispositivos e pode ser demonstrado por meio de determinadas modulações discursivas, conforme o quadro 2.

Quadro 2: Modulações discursivas e mecanismos do racismo

\begin{tabular}{|c|c|c|c|}
\hline \multicolumn{2}{|r|}{ Caso } & Mecanismo & Modulação Discursiva \\
\hline 1 & $\begin{array}{l}2020 \\
\text { Recepcionista negra não aceita tirar } \\
\text { tranças e é demitida de clínica médica }\end{array}$ & - Controle da imagem & $\begin{array}{l}\text { Imagem afro, personificada nas tranças, não } \\
\text { combina com dress code da empresa }\end{array}$ \\
\hline 2 & $\begin{array}{l}2021 \\
\text { Mulher acusa empresa de demiti-la por } \\
\text { "ser macumbeira além de negra". }\end{array}$ & $\begin{array}{l}\text { - Controle da imagem } \\
\text { - Racismo religioso }\end{array}$ & $\begin{array}{l}\text { Prática de religião de matriz africana } \\
\text { não combina com trabalho formal. }\end{array}$ \\
\hline \multirow{2}{*}{3} & $\begin{array}{l}2020 \\
\text { Justiça determina que Atacadão adote medidas } \\
\text { antirracistas após denúncia de funcionária }\end{array}$ & \multirow{2}{*}{$\begin{array}{l}\text { - Outrificação } \\
\text { - Objetificação do corpo negro } \\
\text { - Naturalização da opressão }\end{array}$} & \multirow{2}{*}{$\begin{array}{l}\text { É natural aceitar as agressões racistas } \\
\text { e compreender como parte da cultura e, } \\
\text { para se defender, deve se adaptar. } \\
\text { É comum que o corpo negro seja colocado em um } \\
\text { "não-lugar" e que não haja forma de mudar isso. }\end{array}$} \\
\hline & $\begin{array}{l}2021 \\
\text { Justiça nega pedido para que funcionária seja } \\
\text { recontratada após denunciar preconceito racial }\end{array}$ & & \\
\hline 4 & $\begin{array}{l}2011 \\
\text { Farmácia no Amapá é condenada } \\
\text { por racismo contra funcionária }\end{array}$ & \begin{tabular}{|c|} 
- Miscigenação \\
- Democracia racial \\
- Prejudicar conscientemente \\
vida profissional do negro \\
\end{tabular} & $\begin{array}{l}\text { Quanto mais escuro o corpo, mais } \\
\text { desvantagens no trabalho ele pode ter. }\end{array}$ \\
\hline 5 & $\begin{array}{l}2007 \\
\text { Justiça manda indenizar } \\
\text { recepcionista por racismo }\end{array}$ & $\begin{array}{l}\text { - Animalização } \\
\text { - Desvalorização do trabalho } \\
\text { de corpos negros. }\end{array}$ & $\begin{array}{l}\text { Negro é semelhante ao macaco e seu trabalho vale } \\
\text { menos, por isso, já é muito registrar sua carteira numa } \\
\text { categoria funcional diferente da função exercida. }\end{array}$ \\
\hline 6 & $\begin{array}{l}2002 \\
\text { McDonald's promete pagar R\$12.000 a } \\
\text { ex-funcionária em caso de racismo }\end{array}$ & $\begin{array}{c}\text { - Comunicação violenta } \\
\text { - Consentimento com o racismo } \\
\text { - Associação pejorativa de } \\
\text { características étnicas } \\
\text { - Outrificação }\end{array}$ & $\begin{array}{l}\text { Pretos (e pobres) são fedidos e é natural que } \\
\text { sofram violência, especialmente se o agente } \\
\text { for alguém que não poderá sofrer sanção em } \\
\text { função da sua posição organizacional. }\end{array}$ \\
\hline 7 & $\begin{array}{l}2001 \\
\text { Empresa é condenada por racismo }\end{array}$ & $\begin{array}{c}\text { - Eugenia } \\
\text { - Prejudicar conscientemente } \\
\text { vida profissional do negro } \\
\text { - Anulação do outro } \\
\text { - Consentimento com o racismo }\end{array}$ & $\begin{array}{l}\text { Não se quer negros na área e por isso é preciso } \\
\text { empreender ações para anulá-los deste } \\
\text { ambiente e fazer isso com o apoio organizacional, } \\
\text { consentindo com o gesto racista. }\end{array}$ \\
\hline
\end{tabular}

Fonte: elaborado pelos autores. 


\section{CONSIDERAÇÕES FINAIS}

Os processos corporativos amparam-se em tratados ideologicamente posicionados como progressistas e códigos de conduta que, em geral, não apenas proíbem práticas discriminatórias, como determinam que as empresas as combatam. Algumas ainda expõem certificações e prêmios como destaques na formulação de políticas organizacionais ditas efetivas no combate às diversas opressões, dentre elas, o racismo.

No entanto, nem sempre se mostram efetivas. A resposta a estas dicotomias, demonstradas nas modulações, são contraataques da consciência negra do negro - ou seja, o poder da autodefinição - que, ao processarem e denunciarem a questão, não apenas se rebelam contra a naturalização da opressão, mas tornam-se exemplos de subversão ao sistema que vem sendo construído para anulá-los. Esta é uma característica comum a todos os casos que demonstram a complexa operação articulada da tridimensionalidade do discurso organizacional. Ao se colocar nessa trincheira em todos os aspectos da vida e, em especial, no mundo do trabalho, cada pessoa que se investe de sua própria consciência negra (Mbembe, 2018) e decide exprimi-la, assumindo uma imagem afrocêntrica, passa corporificar o debate e a batalha contra as diversas formas de opressão numa resistência que se ampara na reafirmação identitária como arma. Ao fazer isso, reinscreve e materializa estéticas contra-hegemônicas, afrontando o postulado colonial-racista e a lógica homogeneizadora do capital por três razões: a primeira, é que mostra que o diverso existe e está presente no tecido social e que aquele corpo materializa isso; depois porque tal imagem retoma a ancestralidade africana e expõe-se como signo inconteste de sua origem; e destas duas questões, parece decorrer a terceira, a diversidade e a ancestralidade ressurgidas atacam frontalmente a ideologia racista, o fetiche da imagem ideal eurocentrada.

Temos um espaço de 20 anos entre o primeiro e o último caso e percebemos que, especialmente nesta segunda década do século XXI, tais questões têm se tornado mais visíveis e menos aceitáveis. Isso pode ter uma relação com o avanço do debate racial no Brasil, sendo reflexo de políticas de igualdade racial implementadas em diferentes áreas, especialmente na educação, entre 2002 e 2016, que possibilitaram um aumento da presença de negros e negras no mercado e trabalho, acentuando o conflito racial, que antes era silenciado pela noção de democracia racial, ou seja, esse ideário de que no Brasil não existe racismo.

Percebemos também o quanto as organizações são míopes e coniventes. Muitas, investidas de seus códigos de conduta, que são pródigos em tentar estabelecer na letra parâmetros inaceitáveis de comportamento (homofobia, sexismos, machismo, racismo), utilizam destes dispositivos para reiterar as opressões e safarem-se de ações judiciais, ou seja, não são úteis para aperfeiçoar o sistema organizacional e desenvolver, claramente, políticas de diversidade. Esta dimensão é comprovada em diversas circunstâncias apresentadas nos textos. Dentre elas, percebe-se que na governança corporativa não há, por exemplo, sanção a agentes racistas. Se, de fato, os dispositivos não fossem apenas dialéticos, ao ser registrada uma situação de racismo, uma série de mecanismos seriam ativados, tais como advertência e penalização do agressor, cuidados psicológicos com a vítima, ações coletivas para evitar futuras ocorrências e uma pujante política de comunicação para transformação da cultura organizacional. Entretanto, além de não apresentarem tais ferramentas, as organizações ainda negam os atos racistas e, inclusive, recorrem das ações, reiterando que de fato são coniventes com a situação lamentável.

Há muitos mecanismos para a perpetuação da engenharia racista do pensamento colonial nos contextos organizacionais brasileiros. Transvestida de opinião pessoal e cultura organizacional, constitui várias formas de opressão das pessoas, seja por sua cor, características étnicas, religiosas, gênero, orientação sexual, porte físico, dentre outras, que se somam de forma interseccionada. Talvez deste aspecto decorra a inefetividade das belas declarações de compliance, conduta, ética e sustentabilidade descritas em tantas políticas corporativas. 


\section{REFERÊNCIAS}

BALDISSERA, Rudimar. Comunicação organizacional na perspectiva da complexidade. Organicom, São Paulo, v.6, n.10-11, p115-120, 2009.

BATISTA, Daniela Conegatti; BALDISSERA, Rudimar. Entre a organização comunicada e a "falada": a comunicação organizacional da empresa Tramontina C. B. S/A. Iniciacom, São Paulo, v.2, n.2, 2010.

BÉRGAMO, Mônica. Justiça determina que atacadão adote medidas antirracistas após denúncia de funcionária. Folha de S.Paulo, São Paulo, 30 nov. 2020a. Disponível em: https://wwwl.folha.uol.com.br/colunas/monicabergamo/2020/11/justicadetermina-que-atacadao-adote-medidas-antirracistas-apos-denuncia-de-funcionaria.shtml. Acesso em: 16 jan 2021.

BÉRGAMO, Mônica. Justiça nega pedido para que funcionária seja recontratada após denunciar preconceito racial. Folha de S.Paulo, São Paulo, 6 set. 2020b. Disponível em: https://wwwl.folha.uol.com.br/colunas/monicabergamo/2020/09/justicanega-pedido-para-que-funcionaria-seja-recontratada-apos-denunciar-preconceito-racial.shtml. Acesso em: 16 jan. 2021.

COLLINS, Patricia Hill. Pensamento feminista negro. São Paulo: Boitempo, 2018.

DOMINGUES, Petrônio. Movimento negro brasileiro: alguns apontamentos históricos. Tempo, Niterói, v.12, n.23, p.100-122, 2007.

FANON, Frantz. Pele negra, máscaras brancas. Salvador: EDUFBA, 2008.

FIGUEIREDO, Angela. Carta de uma ex-mulata à Judith Butler. Periódicus, Salvador, v.1, n.3, p.152-169, 2015.

GUIBU, Fábio. Empresa é condenada por racismo. Folha de S.Paulo, São Paulo, 8 out. 2001. Disponível em: https://wwwl.folha. uol.com.br/fsp/cotidian/ff0810200111.htm. Acesso em: 16 jan. 2021.

HOOKS, b. Raça e representação: olhares negros. São Paulo: Elefante, 2019.

JAMISON, Kaline Girão; SANTOS, Adriana Teixeira dos. Modulações do discurso do Michel Temer sobre o papel da mulher: uma análise crítica pragmática-emotiva. Policromias, Rio de janeiro, ano2, p.176-202, 2017.

JUSTIÇA manda indenizar recepcionista por racismo. Folha de S.Paulo, São Paulo, 8 set. 2007. Disponível em: https://www1. folha.uol.com.br/fsp/cotidian/ff0807200712.htm. Acesso em: 16 jan. 2021.

LEITE, Ilka Boaventura. Descendentes de africanos em Santa Catarina: invisibilidade histórica e negação. In: LEITE, Ilka Boaventura (org.). Negros no sul do Brasil. Invisibilidade e territorialidade. Florianópolis: Letras Contemporâneas, 1996. p.5-42.

LODY, Raul. Cabelos de axé: identidade e resistência. Rio de Janeiro: Ed. Senac, 2004.

MARCHIORI, Marlene. Cultura e Comunicação Organizacional: um olhar estratégico sobre as organizações. 2ed. São Caetano do Sul: Difusão, 2008. 
MOORE, Carlos. Racismo e sociedade: novas bases epistemológicas para entender o racismo. Belo Horizonte: Mazza, 2007.

MUNANGA, Kabengele. Negritude: usos e sentidos. São Paulo: Ática, 1988.

OLIVEIRA, Luciana de; MARQUES, Ângela Salgueiro. A imagem de organizações públicas e o sentido de público no discurso de charges sobre Belo Monte. Libero, v.15, n.29, p.59-70, 2012.

OLIVEIRA, Luciana de; SIQUEIRA, Laura Luiza Tupynambá. Teorias do acontecimento e crise organizacional: um diálogo produtivo. Dispositiva, Belo Horizonte, v.2, n.2, p.21-41, 2014.

PINHO, Patricia. Afro-aesthetics in Brazil. In: NUTTALL, Sarah. Beautiful ugly. African and diaspora aesthetics. Durham: Duke University Press, 2006.

RIPARDO, Sérgio. McDonald's promete pagar R\$12 mil a ex-funcionária por racismo. Folha de S.Paulo, São Paulo, 6 dez. 2002. https://wwwl.folha.uol.com.br/folha/dinheiro/ult91u60300.shtml. Acesso em: 16 jan. 2021.

RODRIGO, Pablo. Mulher acusa empresa de demiti-la por ser macumbeira, além de negra. Folha de S.Paulo, São Paulo, 30 nov. 2020. Disponível em: https://www1.folha.uol.com.br/mercado/2020/10/mulher-acusa-empresa-de-demiti-la-por-sermacumbeira-alem-de-negra.shtml. Acesso em: 16 jan. 2021.

SIQUEIRA, Juliana. Recepcionista negra não aceita tirar tranças e é demitida de clínica médica. Folha de S. Paulo, São Paulo, 21 nov. 2020. Disponível em: https://noticias.uol.com.br/cotidiano/ultimas-noticias/2020/11/21/recepcionista-negra-naoaceita-tirar-trancas-e-e-demitida-de-clinica-medica.htm. Acesso em: 16 jan. 2021.

STRUCK, Jean-Philip. Farmácia no Amapá é condenada por racismo contra funcionária. Folha de S.Paulo, São Paulo, 26 ago. 2011. Disponível em: https://www1.folha.uol.com.br/cotidiano/965672-farmacia-no-amapa-e-condenada-por-racismo-contrafuncionaria.shtml. Acesso em: 16 jan. 2021.

Artigo recebido em 29.4.2021 e aprovado em 09.08.2021. 